\title{
"Seguindo em frente!": \\ O fracasso escolar e as classes de aceleração
}

\author{
Fernanda Aparecida Szareski Pezzi \\ Sociedade Educacional Três de Maio (Setrem) - Três de Maio - RS - Brasil \\ Angela Helena Marin \\ Universidade do Vale do Rio dos Sinos - São Leopoldo - RS - Brasil
}

\begin{abstract}
Resumo
Este estudo teve como objetivo caracterizar o trabalho desenvolvido nas classes de aceleração de aprendizagem de uma escola municipal de São Leopoldo - RS, e os efeitos produzidos em adolescentes com histórico de fracasso escolar, em seus pais e nos professores. Trata-se de uma pesquisa qualitativa, descritiva e de caráter transversal. Os participantes constituíram três grupos: 35 adolescentes, 11 pais e três professoras. Os instrumentos utilizados para coleta de dados foram uma Ficha de Contato Inicial e Grupos Focais. Na análise de conteúdo enfatizaram-se as falas referentes às classes de aceleração, das quais derivaram quatro categorias relacionadas ao objetivo do estudo. Os resultados evidenciaram o aumento na autoestima e no desempenho escolar dos alunos, que também tem repercutido nas famílias. Acredita-se que a atuação e o pequeno número de docentes, o estabelecimento do vínculo entre professor e aluno e a mudança na organização curricular e metodológica contribuíram para o sucesso do Projeto.
\end{abstract}

Palavras-Chave: Fracasso escolar; rendimento escolar; classes de aceleração.

\section{Moving forward": The school failure and accelerated classes}

\begin{abstract}
This study aimed to characterize the work in learning accelerated classes in a public school in São Leopoldo - RS, and the effects of it in adolescents with a history of school failure, in their parents and teachers. This is a qualitative, descriptive and transversal research. The participants formed three groups: 35 adolescents, 11 parents and three teachers. The instruments used for data collection were one sheet of initial contact and focus groups. In the content analysis emphasized to the statements regarding the accelerated classes, which are derived four categories related to the purpose of the study. The results showed an increase in self-esteem and better school performance of students, who have also reflected on their families. We believe that the performance and the small number of teachers, the establishment of the link between teacher and student and the change in curriculum and methodological organization contributed to the success of the project.
\end{abstract}

Keywords: School failure; academic achievement; accelerated classes.

\section{“ ¡Siguiendo adelante!”: El fracaso escolar y las clases de aceleración}

\section{Resumen}

Este estudio tuvo como objetivo caracterizar el trabajo desarrollado en las clases de aceleración de aprendizaje de una escuela municipal de São Leopoldo - RS, y los efectos producidos en adolescentes con histórico de fracaso escolar, en sus padres y en los profesores. Se trata de una investigación cualitativa, descriptiva y de carácter transversal. Los participantes constituyeron tres grupos: 35 adolescentes, 11 padres y tres profesoras. Los instrumentos utilizados para colecta de datos fueron una Ficha de Contacto Inicial y Grupos Focales. En el análisis de contenido se enfatizólas hablas referentes a las clases de aceleraciones, de las cuales derivaron cuatro categorías relacionadas al objetivo del estudio. Los resultados evidenciaron el aumento en la autoestima y en el desempeño escolar de los alumnos, que también ha repercutido en las familias. Se cree que la actuación y el pequeño número de docentes, el establecimiento de vínculo entre profesor y alumno y el cambio en la organización curricular y metodológica contribuyeron para el éxito del Proyecto.

Palabras clave: fracaso escolar; rendimiento escolar; clases de aceleración. 


\section{Introdução}

A reprovação pode ser entendida como um fenômeno mundial de longa data que afeta a grande maioria dos países do mundo, caracterizando-se assim como um dos maiores problemas dos sistemas escolares (Torres, 2004). Ao considerar o Brasil, Ribeiro (1991) considera que a repetência está na própria origem da escola brasileira, de maneira que passou a ser aceita por todos os agentes da escola como um processo natural. Tal fato se mostra como um problema, visto que a repetência tende a provocar novas reprovações, levando ao fracasso escolar, o que contraria a ideia de que repetir o ano escolar ajudaria o aluno a progredir nos estudos (Crahay, 2006; Jacomini, 2010; Ribeiro, 1991).

Por muitos anos, os alunos que fracassavam não permaneciam na escola, mas hoje a realidade é oposta (Bahia, 2009; Pasian, Vestrone, \& Caetano, 2012), tendo em vista a legislação nacional vigente (Lei n. 9.394,1996; Lei 12.796, 2013), que prevê a obrigatoriedade do ensino dos quatro aos 17 anos de idade. Entretanto, não há garantias de que, de fato, todos os alunos tenham acesso aos conteúdos e às atividades para desenvolver as habilidades necessárias em cada ano escolar (Pasian \& cols., 2012; Jacomini, 2010). Considerando essas questões, no presente trabalho optou-se por utilizar o conceito de fracasso escolar, para se referir à distorção entre idade e ano (Lei n. 9.394,1996; Resolução CNE/CEB n. 4, 2010; Parecer CNE/CEB n. 7, 2010) de dois ou mais anos de ensino (SMED-SL, 2012), que decorre de sucessivas reprovações.

Nesta perspectiva, é importante considerar as duas formas de exclusão descritas por Ferraro $(1999,2004)$ e que estão presentes no sistema educacional: a exclusão da escola e a exclusão na escola. Enquanto a primeira se refere ao não acesso à escola, bem como à evasão escolar, a segunda trata de uma exclusão operada dentro do sistema educacional, através do mecanismo da reprovação (Ferraro, 1999, 2004). Reconhece-se, assim, que essas duas formas de exclusão trazem sofrimento e consequências futuras para os alunos.

Franco e Davis (2011) relataram a história de um jovem com histórico de reprovações e abandono escolar, em que se constataram as marcas deixadas na sua consciência pelo não aprender e a sua consequente entrada no mundo das drogas. A literatura corrobora esse estudo à medida que indica que os alunos que vivenciam o fracasso escolar também revelam maior risco de gravidez na adolescência e envolvimento com drogas, criminalidade e violência (Lucio, Hunt, \& Bornovalova, 2012; Rumberger, 2011). Assim, esse fenômeno pode ser caracterizado não só como um problema educacional (Bastos, Fernandes, \& Passos, 2009), como também uma questão de saúde pública (Lucio \& cols., 2012), merecendo atenção dos psicólogos, uma vez que o sofrimento gerado e vivido nos relacionamentos escolares, especialmente o advindo do fracasso escolar, é testemunhado e relatado por clínicos (Bossa, 2002).

Como uma alternativa para correção do fluxo escolar, a fim de recuperar a trajetória dos alunos com distorção ida- de-ano foram implantadas em todo o país classes de aceleração da aprendizagem, conforme orienta a Lei de Diretrizes e Bases da Educação Nacional (LDB) n. 9.394/1996, a Resolução CNE/CEB 4/2010, a Resolução CNE/CEB 7/2010 e o Parecer CNE/CEB 7/2010 do Conselho Nacional de Educação. De acordo com a Resolução CNE/CEB 4/2010, Art. 49, a aceleração dos estudos destina-se aos alunos com atraso escolar, que apresentam descompasso de idade, em função de entrada tardia, retenção, dificuldades no processo de ensino-aprendizagem, dentre outros.

$\mathrm{Na}$ literatura, encontram-se alguns estudos que buscaram compreender a implantação das classes de aceleração em diferentes estados brasileiros, como em Santa Catarina (Hanff, Barbosa, \& Koch, 2002) e São Paulo (Bahia, 2009; Placco, André, \& Almeida, 1999). Bahia (2009) e Hanff e cols. (2002). Esses estudos pontuaram a existência de problemas na implementação das classes de aceleração, uma vez que constataram a falta de envolvimento efetivo de toda a escola e de um acompanhamento sistemático da proposta, o que fez com que a exclusão permanecesse no sistema educacional (Bahia, 2009). Por outro lado, Placco e cols. (1999) destacaram os efeitos positivos na autoestima e no desempenho escolar de alunos egressos das classes de aceleração, visto que se observou que esses alunos normalmente tinham dificuldades de várias ordens, como por exemplo, emocionais e comportamentais. Dessa forma, os autores concluíram que se torna muito difícil recuperar em um único ano as deficiências que vêm sendo acumuladas por muito tempo e que extrapolam o universo escolar (Placco \& cols., 1999).

Conforme orienta a legislação, cada estado ou município organiza o projeto das classes de aceleração da aprendizagem em nível local. No estado de São Paulo, de acordo com Placco e cols. (1999), essas classes têm como objetivo eliminar a defasagem idade-série criando condições para que os alunos avancem no percurso escolar e possam frequentar uma série compatível com a sua idade. Nesta perspectiva, a ênfase recai sobre as potencialidades dos alunos, a partir dos conhecimentos prévios que cada um possui e na interação entre professor-aluno. Através de um trabalho intencional e flexibilizado com a participação do aluno, se propõe resgatar a sua autoestima, possibilitando a aprendizagem e o desenvolvimento de habilidades necessárias para a sua reintegração à escola (Placco \& cols., 1999).

Nessa perspectiva, se encontra o "Projeto Seguindo em Frente - 2012" elaborado pela Secretaria Municipal de São Leopoldo - RS, com vistas à correção do fluxo escolar através da aceleração da aprendizagem, numa abordagem interdisciplinar e de uma consequente reestruturação curricular. O projeto está organizado de modo a contemplar os conteúdos obrigatórios previstos na legislação para cada nível de ensino, os recursos de pessoal e materiais necessários, uma metodologia de ensino direcionada para interdisciplinaridade e para valorização dos conhecimentos anteriores e para trajetória de vida dos alunos matriculados nessas classes (SMED-SL, 2012). Também estão previs- 
tos critérios para seleção das escolas, dos professores e o acompanhamento pedagógico da Secretaria de Educação.

Diante do exposto, evidencia-se que ainda são poucos os estudos que investigaram o funcionamento das classes de aceleração e, principalmente, os efeitos produzidos sobre os alunos que delas participam. Nesse sentido, este trabalho teve como objetivo caracterizar o trabalho desenvolvido nas classes de aceleração da aprendizagem de uma escola municipal de São Leopoldo - RS, e os efeitos produzidos em adolescentes com histórico de fracasso escolar, seus pais e professores.

\section{Método}

\section{Delineamento}

Trata-se de uma pesquisa descritiva transversal, de abordagem qualitativa. De acordo com Flick (2009), as pesquisas qualitativas centram seu interesse sobre o significado que os participantes atribuem à questão em estudo e implicam uma postura interpretativa e naturalística do pesquisador. Já as pesquisas descritivas são úteis para mostrar os ângulos ou dimensões de um fenômeno, de uma comunidade, de um contexto ou de uma situação (Sampieri, Callado, \& Lucio, 2013).

O presente estudo faz parte de uma pesquisa maior, intitulada Fracasso escolar: sintoma e/ou reatividade ao sistema de ensino ${ }^{1,}$ coordenada pela Profa. Dra. Angela Helena Marin. Este tem como objetivo avaliar os fatores individuais, familiares e escolares e sua inter-relação com a produção do fracasso escolar em adolescentes do ensino fundamental.

\section{Participantes}

Participaram da pesquisa três grupos distintos: 35 adolescentes, 11 pais e três professoras. Os adolescentes foram divididos em cinco grupos; os pais formaram dois grupos; e as professoras constituíram um único grupo, composto por três delas.

Os adolescentes tinham entre 14 e 17 anos ( $\mathrm{M}=$ $15,6 \mathrm{SD}=0,73$ ), sendo 18 do sexo masculino e 17 do sexo feminino, e estavam regularmente matriculados no ensino fundamental de uma escola da rede municipal da cidade de São Leopoldo/RS. Eles foram selecionados por conveniência, considerando o critério da matrícula em uma classe de aceleração da aprendizagem devido a apresentarem distorção idade e ano escolar (Lei n. 9.394, 1996; Resolução CNE/CEB n. 4, 2010, Parecer CNE/CEB n. 7, 2010) de dois ou mais anos de ensino (SMED-SL, 2012). Como a escola em questão possuía duas classes de aceleração, os adolescentes de ambas as turmas foram convidados a participar.

1 Projeto financiado pelo Conselho Nacional de Desenvolvimento Científico e Tecnológico (CNPq).
Também participaram 11 pais, representados por 10 mães e um pai. Todos que possuíam um filho/a matriculado/a nas classes de aceleração foram convidados a participar do estudo $(N=41)$ e aqueles que se interessaram compuseram o grupo $(n=11)$. A maioria não possuía o ensino fundamental completo $(n=9)$, tinha trabalho remunerado $(n=8)$ e grande parte das famílias era numerosa, com quatro ou mais filhos $(n=7)$. O grupo de professoras foi composto por três participantes, que aceitaram participar do estudo, do total de quatro que trabalhavam nas classes de aceleração da aprendizagem. Elas tinham, em média, 12 anos de docência e duas delas já trabalhavam há três anos nas classes de aceleração, enquanto a terceira estava na sua primeira experiência com essas turmas.

\section{Instrumentos}

Ficha de Contato Inicial: este instrumento teve como objetivo registrar os dados do adolescente, da escola e do/a professor/a, bem como o endereço e o telefone das famílias para contato posterior.

Grupo Focal: este instrumento visou obter dados por meio de discussões, em que os participantes expressassem suas opiniões sobre a dinâmica das classes de aceleração de aprendizagem, buscando caracterizar o trabalho realizado nestas classes e os efeitos deste trabalho em uma escola de São Leopoldo - RS. Trata-se de um instrumento que tem sido utilizado em diferentes áreas do conhecimento e circunstâncias nas quais, a partir de um guia de tópicos (roteiro), o pesquisador estimula a interação entre os participantes (Barbour, 2009). Os grupos focais contaram com a presença de uma moderadora (pesquisadora) e também de uma moderadora assistente.

\section{Procedimentos Éticos e de Coleta de Dados}

A presente pesquisa foi aprovada pelo Comitê de Ética em Pesquisa (CEP) da Universidade do Vale do Rio dos Sinos sob o protocolo $\mathrm{N}^{\circ} 12 / 084^{2}$. O Termo de Consentimento Livre e Esclarecido (TCLE) foi assinado pelos adolescentes, pais e professores, sendo que para a participação na pesquisa dos adolescentes, além deles próprios assentirem, também se obteve a autorização de seus pais ou representante legal.

Após a aprovação pelo Comitê de Ética, foi realizado o contato com a Secretaria Municipal de Educação de São Leopoldo/RS para apresentar a proposta do estudo e obter a autorização para a sua realização. Uma vez concedida a autorização, planejou-se a realização da coleta de dados. Para tanto, uma escola municipal que possuía classes de acele-

2 Todos os princípios e cuidados éticos necessários à pesquisa com seres humanos foram assegurados aos participantes, conforme a Resolução 016/2000, do Conselho Federal de Psicologia, e a Resolução 466/12, do Conselho Nacional de Saúde. 
ração da aprendizagem foi contatada para apresentação da pesquisa e, a partir do aceite em participar, foi assinada pela direção da escola a Carta de Anuência para a realização do estudo. Em seguida, na própria escola, foi realizado o convite aos adolescentes com histórico de fracasso escolar e àqueles que se interessaram em participar foi entregue o TCLE, o qual seus pais também deveriam assinar, além de uma breve Ficha de Contato Inicial, para viabilizar o contato posterior. Da mesma forma, as professoras foram convidadas a participar do estudo e assinaram ao TCLE.

Em seguida, verificou-se com a direção da escola a disponibilidade de salas e horários para a realização dos grupos focais. Todos os adolescentes, pais e professoras das classes de aceleração da aprendizagem foram contatados, a fim de convidá-los para participar de um grupo focal com data e horário previamente determinado, considerando a disponibilidade de todos. Os grupos com adolescentes e com as professoras aconteceram no período da tarde, enquanto que os grupos com pais foram agendados no turno da noite. Como o grupo constitui a unidade de análise, optou-se por garantir que seus participantes compartilhassem de pelo menos uma característica (Barbour, 2009). Nesse sentido, os participantes foram o critério de composição dos grupos, de modo que foram realizados cinco grupos focais com os adolescentes, dois com os pais e um com as professoras.

No início de cada grupo focal, foi realizado um rapport, retomando e assegurando todos os princípios éticos da pesquisa envolvendo seres humanos. Os grupos foram compostos por três a oito participantes, considerando a importância de que fossem pequenos o suficiente para que todos pudessem partilhar as suas percepções, e grande o suficiente para contemplar a diversidade entre eles (Oliveira \& Freitas, 1997). A duração de cada grupo focal variou de 30 a 100 minutos.

\section{Análise dos Dados}

O material produzido nos grupos focais foi gravado, transcrito na íntegra e examinado por meio da análise de conteúdo qualitativa (Bardin, 1977; Laville \& Dionne, 1999), considerando a linguagem verbal dos participantes. Para a análise, foi adotado o modelo de categorias temáticas, que preconiza os seguintes passos: 1) pré-análise (fase de organização dos dados, na qual se faz a leitura flutuante, a elaboração de indicadores e a preparação do material); 2) exploração do material (consiste essencialmente em codificar o material); e 3) tratamento dos resultados, inferência e interpretação (atribuição de significados aos dados).

\section{Resultados}

Para análise de conteúdo qualitativa enfatizaram-se as falas referentes às classes de aceleração da aprendizagem, que fazem parte do projeto desenvolvido pela Secretaria de Educação de São Leopoldo-RS, chamado Seguindo em Frente.
Dessas falas derivaram as seguintes categorias referentes às suas percepções sobre: a) características do projeto; b) diferenças entre as classes seriadas e as classes de aceleração; c) efeitos das classes de aceleração nos alunos; d) atuação das professoras das classes de aceleração. Os dados foram analisados utilizando o software Nvivo10. O cálculo da concordância foi feito considerando a avaliação de dois juízes que classificaram, separadamente, $20 \%$ do total das falas classificadas em cada grupo focal ${ }^{3}$. O índice entre os juízes foi calculado e o valor médio obtido foi de $87 \%$ para os grupos dos adolescentes, $96,5 \%$ para os grupos dos pais e $82,1 \%$ para o grupo das professoras, os quais são considerados excelentes, segundo Robson (1995).

As falas que ilustram as categorias não foram identificadas a fim de preservar a identidade dos participantes. Dessa forma, para se referir aos grupos focais de adolescentes, utilizou-se a sigla GA, acompanhada do numeral 1 ao 5 , que indica o grupo no qual a fala foi pronunciada. Foram usadas também as siglas GP, para o grupo de pais, acompanhadas dos números 1 e 2, e a sigla GPr para o grupo de professoras.

A primeira categoria contemplou o que cada grupo sabia sobre o projeto que envolvia as classes de aceleração da aprendizagem realizadas na escola. Os adolescentes o caracterizaram como uma oportunidade de terminar o ensino fundamental, recuperar os anos escolares devido às reprovações e aprender de fato os conteúdos: "A gente recuperou os anos perdidos, num ano só” (GA3), "Me esforcei mais pra avançar, recuperar os anos perdidos, não faltei mais aula" (GA5). Os pais, por sua vez, destacaram o projeto como uma oportunidade para os filhos continuarem seus estudos: "Fazer que nem o $A$. tá fazendo a $7^{a}$ e a $8^{a}$, pra eles não ficar tipo 16, 17 anos, fazendo a $7^{a}$ e a $8^{a}$. Então fizeram o acelera!" (GP1). Enquanto que, as professoras apresentaram como funciona o projeto, explicando que se trata de uma proposta interdisciplinar, na qual quatro professoras trabalham de forma integrada. Nesse projeto, tem-se como objetivo desenvolver aspectos relacionados à vida dos adolescentes: "Tentar tirar eles de cena: olha de fora como que é! Aí eles desenvolveram pesquisas, artigos de opinião" (GPr); "Três anos de projeto, três diferentes. Três levas de alunos, assim, diferentes" (GPr).

$\mathrm{Na}$ segunda categoria, "Diferenças entre as classes seriadas e as classes de aceleração", os adolescentes destacaram, em todos os grupos, a mudança na forma como as professoras do projeto conduziam as aulas: "As professoras são mais amigas" (GA1), "Elas explicam tipo, quando um não sabe, ela vai lá senta do lado. Ajudam, explicam, se não entendeu explica de novo!" (GA2). Também falaram de uma metodologia diferenciada e da exigência para aprender associada ao carinho: "Aqui é uma equipe! Estamos todos juntos!" (GA3), "A matéria é tudo igual. O carinho também é igual!" (GA3), "Aprende se divertindo" (GA4). Eles ainda ressaltaram a importância do trabalho em grupos: "Tipo

3 As falas de todos os grupos realizados, respeitada a divisão entre adolescentes, pais e professores, foram consideradas para esse cálculo. 
fazer trio, daí é que nós começamos a conviver, né? Que nós aprendemos!" (GA2), "A diferença foi os colegas. São mais interativos, mais aproximação. Quando eu estava na $5^{a}$ série eu não falava com ninguém. Eu aprontava muito, brigava muito, eu era terrível nessa época!" (GA1); e que ter apenas quatro professoras favorece o vínculo: "Por causa que nas classes seriadas é um dia uma professora diferente. No acelera são só quatro!" (GA2). Por fim, destacaram como único aspecto negativo o preconceito que sofrem por estudarem nas classes de aceleração, mesmo que já estivessem trabalhando para superá-lo: "As nossas profes me ensinaram a lidar com isso [preconceito contra o acelera]. A gente também é formando igual. A gente faz coisa com a $8^{a}$ série igual. O que a $8^{a}$ série faz a gente também faz, às vezes até melhor!" (GA3).

Já os pais afirmaram que as professoras são um importante diferencial entre as classes seriadas e de aceleração: "É a cobrança dos professores, porque na sala de aula normal os professores muito pouco puxam" (GP2), "As professoras do acelera não, elas colam do lado da classe: vem fazer, vamos fazer!" (GP2). Também ressaltaram a importância do vínculo estabelecido entre seus filhos e as professoras: "É amiga! Toda hora estão conversando! Toda hora" (GP2), "Elas têm os números [de telefone] deles!" (GP2).

Ao falar sobre as diferenças entre as classes seriadas e as classes de aceleração, uma professora destacou o primeiro impacto quando foi convidada a trabalhar no projeto: "Meu Deus! Eu não vou saber dar aula pra esse Acelera, me deu uma agonia, mas, enfim, até que eu sei! Eu me formei pra isso! Então vamos ver no que vai dar! Eu gostei! Sabe que até é bem bom!" (GPr). Destacaram com alegria o modo como realizavam o trabalho nessas classes: "A gente tem uma autonomia” (GPr), "(...) a gente embarca nos projetos e vamos todo mundo!" (GPr), "Eu gosto de contar os babados da história pra eles. Eu tento fazer de uma forma diferente! É uma aprendizagem significativa! Como é que não gostam de história se cada um tem a sua história?" (GPr); e também o vínculo estabelecido com os alunos: "A gente fica muito mais tempo com eles e isso cria vínculo" (GPr). Também referiram à dificuldade de fazer um trabalho interdisciplinar nas classes seriadas e a questão da carga horária, em função de ter poucas aulas por semana, dificultando, assim, o contato com os alunos: "A gente não consegue chegar numa unanimidade de trabalho!" (GPr), "Outra [dificuldade] é a carga horária" (GPr). Assim como os alunos falaram do preconceito contra as classes de aceleração na escola, as professoras também o pontuaram, se referindo a uma briga entre os alunos das classes de aceleração: "É que quando acontece com os alunos do Acelera parece que é maior. É espetáculo daí!" (GPr), "O simples fato de ser classificado, né? Ah, o aluno repente vai para o Acelera! Como se aqui fosse um depósito. Aqui não é um depósito!" (GPr).

A terceira categoria, "Efeitos nos alunos das classes de aceleração", envolveu as falas referentes às mudanças percebidas nos adolescentes, por eles próprios, seus pais e professores a partir da inserção no projeto. Os adolescentes contaram sobre as mudanças que vivenciaram: "Eu acho que esse projeto que nós entramos melhorou um pouco pra nós porque tipo, báh! Eu estava todo dia na diretoria! Não sou mais daqueles! Só volta e meia eu faço umas coisinhas, converso!" (GA2), "Porque agora a profe R. pegou no meu pé! Todas as profes agora pegaram no meu pé! Aí depois eu fui devagar e estou gostando! Foi difícil! Eu atirava minhas coisas no chão de raiva!" (GA1), "Agora é MS! Nós é MS [muito satisfatório]!” (GA2). Eles também se referiram sobre como se sentiram no projeto: "Mais importante do que na $6^{2}$ série!" (GA4), "Mais inteligente!" (GA4), "Me senti um bom aluno! Agora eu fiz amigos!" (GA1).

Os pais comentaram sobre o sentimento de surpresa com a melhora do desempenho escolar dos filhos: "Eu me surpreendi com ele, porque eu disse assim pro meu marido: não vai passar esse ano, porque são três séries juntas, né? Aí quando eu peguei o boletim, os dois primeiros, estava tudo MS!" (GP1), "A N. agora mudou. Esse ano!" (GP1), "Antes o A. amanhecia fazendo o trabalho. Agora não! Agora se o trabalho é pra semana que vem, ele já começa essa semana. Vai fazendo, vai se interessando!" (GP1). Relataram, ainda, o aprendizado que os filhos tiveram e a motivação que manifestaram: "Aprender a respeitar professores, colegas, respeito entre eles do grupo. Foi bem melhorando agora no acelera!" (PG2), "Motivou eles!" (PG2), "Colocou a autoestima, principalmente as professoras, deles pra cima!" (GP2), "Esse acelera foi um dos melhores projetos da escola!" (GP2), "Toda criança precisa de um incentivo desses que nossos filhos tiveram!" (PG2), "Estou muito feliz com a minha filha, por tudo que ela tá passando nessa vida. Ela é uma vitoriosa" (PG2).

As professoras também destacaram as mudanças que perceberam nos alunos: "Essa gurizada é assim! Realmente voltaram a criar uma identidade de estudante, que podia ir lá, apresentar, erguer a cabeça, falar e gostar da escola. Começaram a enxergar a escola não só como onde eu encontro meus amigos, mas um lugar onde realmente eu posso aprender, eu posso ter uma perspectiva!" (GPr). Elas destacaram aspectos que contribuíram para as mudanças nos alunos, como a relação professor-aluno, o respeito e aspectos relacionados ao cotidiano: "Foi muito bacana, porque esses alunos se tornaram nossos aliados. Nós defendíamos eles e eles nos defendiam!" (GPr), "A palavra que comanda essa história é respeito. Eles aprenderam realmente a respeitar e eles sabem que eles estão respeitando. Não é por causa de uma nota!" (GPr).

Na quarta e última categoria, "Atuação das professoras das classes de aceleração", foram classificadas as falas que se referiram ao modo como as educadoras conduziam o trabalho nessas classes. Os adolescentes mencionaram as características pessoais das professoras e o modo como o trabalho era realizado: "Elas tratam todos do mesmo jeito! Tipo tem uns que já estão quase rodado, elas vão lá, sentam do lado e conversa" (GA2), "Mesmo que tenha que explicar 10 vezes, elas explicam" (GA4), "São mais amigas" (GA1). Também falaram sobre a vontade de desistir, quando ingressaram nas classes e a importância do incentivo das 
professoras: "Depois que tu entra na sala, as profes viram tua cabeça, porque elas são muito legais, daí tu resolve ficar. Tu mesma! Ninguém te força a nada!" (GA3).

Os pais também descreveram suas percepções: " $A$ minha filha ama os professores dela" (GP2), "Se tivesse duas professoras pra cada aluno iguais às do acelera, teria melhores escolas" (GP2). Reportaram ainda como são bem recebidos pelas professoras: "Elas são muito queridas" (GP2), "Agora a professora R. disse que a G. participa, faz as coisas, ... Fico feliz de ouvir isso dela!” (GP1).

As professoras, por sua vez, relataram que reconheciam uma modificação na sua forma de dar aula: "Eu agora mudei o meu jeito de dar aula. Eu já acho que aqui vai ser, foi a minha escola [se referindo à aceleração]. Aqui eu aprendi muita coisa!", "Outra coisa que eu acho que é bacana é que a gente não compara o fulano que não sabe com o fulano que sabe tudo. Nós comparamos o fulano com o fulano mesmo, com o crescimento dele mesmo" (GPr). Uma professora mencionou: "Eu me despi totalmente daquilo tudo que eu já tinha, já trazia deles. Eu disse deu, sai pra lá, deixa isso de lado, esquece tudo isso e aí eu consegui!" (GPr). Quando questionadas sobre como se sentiam nas classes, uma professora afirmou: "Eu me sinto realizada! Eu sou professor de carteirinha! Sou professor, quero ser, escolhi essa profissão. Então, pra ser professor, tu precisa tá em construção porque a educação tá sempre em transformação! (GPr).

\section{Discussão}

O presente estudo buscou caracterizar o trabalho desenvolvido nas classes de aceleração da aprendizagem de uma escola municipal de São Leopoldo - RS, e os efeitos produzidos em adolescentes com histórico de fracasso escolar, seus pais e professores. Constatou-se que o "Acelera", como é carinhosamente denominado o projeto de aceleração da aprendizagem da escola pesquisada, tem obtido bons resultados no que se refere ao desempenho escolar e desenvolvimento da autoestima dos alunos, que servem para reflexão acerca de possibilidades de prevenção e intervenção junto ao fracasso escolar. Como já referido, os adolescentes matriculados nas classes de aceleração tinham um histórico de reprovação de dois ou mais anos de ensino (SMED-SL, 2012). Nas palavras de uma professora, tratava-se de adolescentes que já não tinham mais uma "identidade de estudante". Desse modo, viviam um processo de exclusão na escola, conforme destacado por Ferraro (1999, 2004).

$\mathrm{Na}$ categoria que se referiu às características do projeto, adolescentes, pais e professores destacaram a importância das classes de aceleração da aprendizagem como uma possibilidade de recuperar os anos escolares perdidos. Foi possível observar que o fato de serem desafiados a cursar vários anos ao mesmo tempo, permitiu que eles passassem a acreditar em suas potencialidades. As professoras que estavam vinculadas ao projeto salientaram como aspectos importantes o trabalho interdisciplinar, o pequeno grupo de trabalho entre as docentes e o conhecimento sobre a realidade dos alunos, o que possibilitou que as propostas de ensino fossem modificadas a cada ano, a fim de contemplar o interesse de cada turma. As temáticas trabalhadas envolviam os conhecimentos e os componentes curriculares obrigatórios para cada ano escolar, porém também adquiriram um caráter interdisciplinar voltado à realidade de vida dos adolescentes.

Ao discorrerem sobre as diferenças entre as classes seriadas e as classes de aceleração os adolescentes e pais foram unânimes em destacar o papel dos professores no processo de ensino-aprendizagem. Os adolescentes afirmaram que se sentiram acolhidos e capazes, reconheceram a importância da coesão grupal, o que possibilitava o companheirismo e a amizade entre os colegas. $O$ discurso dos pais foi bastante semelhante ao de seus filhos, revelando a existência do diálogo entre eles.

A fala dos adolescentes corrobora o que foi referido em uma pesquisa realizada com 33 alunos americanos com risco de abandono escolar que haviam trocado de uma escola tradicional para outra que oferecia uma proposta pedagógica diferenciada (Lagana-Riordan \& cols., 2011). Os dados obtidos a partir de uma entrevista apontaram que as dificuldades vivenciadas na escola tradicional se referiam a falta de atenção individual do professor ao aluno em função das turmas serem numerosas, além do sentimento de serem rotulados e julgados pelos professores e colegas em função de suas dificuldades, o que propiciava o bullying. Tal percepção era diferenciada da que tinham da escola que estavam frequentando naquele momento, a qual conseguia atender as suas dificuldades.

Da mesma forma, o relacionamento professor e aluno nas classes de aceleração foi ressaltado no estudo realizado por Bahia (2009), que indicou que os professores demonstraram maior envolvimento e comprometimento com os alunos que haviam vivenciado o fracasso escolar, buscando entendê-los em suas dificuldades. Eles também se mostraram mais tolerantes em relação aos comportamentos inadequados, demonstrando afetividade e prazer no seu fazer. Franco e Davis (2011), ao refletirem sobre a construção social da autoestima no processo de ensino-aprendizagem, apontaram o acolhimento e valorização sentidos pelos alunos nas classes de aceleração, o que possibilitava a modificação do comportamento e de postura enquanto estudantes.

A modificação da postura como estudantes também foi observada em grande parte dos adolescentes investigados no presente trabalho, como foi revelado na terceira categoria. Nesta perspectiva, destaca-se que a autoestima depende das condições de vida do sujeito e também de uma escola de boa qualidade (Franco \& Davis, 2011), pois existe uma relação positiva entre a autoestima e o desempenho acadêmico (Alam, 2013). Quando um aluno consegue alimentar uma expectativa positiva para o futuro com relação aos seus estudos, surgem também sentimentos que podem exercer um papel motivacional capaz de conduzir a comportamentos específicos, como a retomada da vontade de aprender (Bzunek \& Sales, 2011). 
Com base no trabalho realizado junto às classes de aceleração da aprendizagem ficou evidente o quanto os professores trabalhavam para mostrar aos adolescentes que eles podiam e conseguiam aprender, já que muitos, devido a tantas reprovações, já se sentiam incapazes de realizar as atividades propostas (Pasian \& cols., 2012). Era justamente para modificar esse sentimento de desvalia que as professoras trabalhavam.

Evidenciou-se, ainda, na categoria "Atuação das professoras das classes de aceleração", a postura diferenciada que essas profissionais assumiram diante do fracasso escolar, considerando a relação professor-aluno-família e a metodologia de trabalho voltada para interdisciplinaridade e com temáticas que contemplavam a realidade daqueles alunos. Ireland e cols. (2007) destacaram que a relação que se estabelece entre o professor e o aluno é relevante para o desempenho escolar, pois o clima da sala de aula é basicamente definido pelo próprio professor, uma vez que ele detém o controle do processo, estabelecendo metodologias, conteúdos, avaliações e também as formas como as relações se darão neste contexto. Osti e Brenelli (2013) destacaram que no processo educativo mobilizam-se aspectos cognitivos, mas também afetivos, que têm relação com quem se construirá o saber. Por exemplo, ao vivenciarem relações positivas, os alunos sentem-se confortáveis e seguros, o que favorece a aprendizagem (Osti \& Brenelli, 2013). Assim, entre os fatores de proteção no contexto escolar a relação professor-aluno assume uma importância fundamental, uma vez que a partir de uma relação pautada pela confiança e pelo afeto é possível estimular uma escolarização positiva (Nunes, Pontes, Silva, \& Dell'Aglio, 2014).

Além disso, Walkey, McClure, Meier e Weir (2013) pontuaram que alunos que manifestavam pretensões futuras relacionadas a aspirações educacionais apresentavam melhores desempenhos acadêmicos. Dessa forma, cabe à escola e a família dar primazia aos objetivos futuros, mas possíveis, considerando que eles podem afetar o comportamento e influenciar os resultados escolares e profissionais (Walkey \& cols., 2013). Nunes e cols. (2014) apontaram que quando os alunos percebem a escola de uma forma mais positiva tendem a apresentar expectativas educacionais melhores para seu futuro. O projeto "Seguindo em frente" tem cumprido com este objetivo, uma vez que os alunos passaram a acreditar em seu potencial e ter perspectivas futuras, o que contribuiu efetivamente para uma mudança. Considerando a abordagem sistêmica, acredita-se que essa modificação no sistema aluno, pode acarretar mudanças nos demais sistemas envolvidos - família e escola (Vasconcellos, 2012).

Contudo, os adolescentes e professores destacaram os preconceitos contra as classes de aceleração e o descaso que sofrem na escola devido ao histórico de fracasso escolar. Existe uma concordância sobre o fato de essas classes não poderem ser um depósito e nem serem permanentes, visto que revelam algo que não está bem, nesse caso, a permanência do fracasso escolar. Como referem Franco e Davis (2011), as classes de aceleração são para alguns alunos 'um oásis no deserto', uma vez que a escola é para muitos alunos como 'um remédio amargo'. Assim, parafraseando a fala de uma professora, pode-se questionar: "como é possivel tornar a escola um lugar onde eu tenho amigos, posso aprender e ser feliz?"

Destaca-se, por fim, que, por muito tempo, os psicólogos contribuíram com a área da educação por meio da elaboração de avaliações e laudos psicológicos, cuja finalidade era medir a capacidade dos alunos e, assim, classificá-los como aptos ou não aptos ao processo de aprendizagem (Guzzo, Mezzalira, Morreira, Tizzei, \& Neto, 2010; Patto, 1990). Atualmente, vive-se, um momento em que se busca superar essa posição de individualização do fracasso escolar, cabendo aos psicólogos contribuir com os educadores para a promoção da aprendizagem e do desenvolvimento dos alunos através de uma perspectiva mais sistêmica, considerando além do desenvolvimento cognitivo, o emocional e o social por meio de intervenções que contemplem os alunos, suas famílias e a comunidade escolar (Guzzo \& cols., 2010).

\section{Considerações finais}

A partir da realização da presente pesquisa pode-se evidenciar a efetividade e o sucesso do projeto que implementou as classes de aceleração da aprendizagem na escola estudada, a partir do ponto de vista dos seus participantes. O relato dos adolescentes, seus pais e professoras apresentaram uma visão semelhante e articulada aos fatos que vivenciavam e de como percebiam o trabalho realizado.

Seguindo em frente! Eis o lema, que já se coloca como um marco na escola e que os adolescentes repetiram com propriedade. Tal proposta foi percebida por todos como uma oportunidade de recuperar os anos de estudo perdidos e ter uma melhor perspectiva de futuro. Assim, acredita-se que a atuação e o número reduzido de professores, o estabelecimento de um vínculo entre professores e alunos e a mudança na organização curricular e metodológica, que possibilitou a realização de um projeto interdisciplinar com enfoque em temas e aprendizados relacionados ao conhecimento prévio e a realidade dos alunos, contribuem para o sucesso do projeto. Além disso, é importante salientar o quanto a fala dos adolescentes e de seus pais revelou o sofrimento e o descrédito que sentiam após anos de sucessivas reprovações, o que foi modificado com a inserção nas classes de aceleração da aprendizagem, por meio do resgate da autoestima e da crença nas suas capacidades.

Ao finalizar este estudo, emergem diferentes sentimentos e questões. Muito se tem estudado e dito sobre o fracasso escolar, mas até quando essa realidade assombrará o sistema de ensino? Sabe-se que as classes de aceleração se constituíram em todo país como uma política "remediativa" a essa questão, entretanto, muitos alunos continuam sendo excluídos do processo educacional. De acordo com Ferraro (1999, p.24) não se trata simplesmente de "caçar os fujões ou puxar as orelhas dos preguiçosos". Pelo contrário, 
refere-se ao comprometimento da escola e da comunidade na busca de alternativas que não permitam que aconteça o fracasso escolar, pois ele é responsabilidade de todos!

\section{Referências}

Alam, M. (2013). A study of test anxiety, self-esteem and academic performance among adolescents. The IUP Journal of Organizational Behavior, 12 (4), 33-43.

Bahia, N. P. (2009). Formação de professores em serviço: Fragilidades e descompassos no enfrentamento do fracasso escolar. Educação e Pesquisa, 35(2), 317-329.

Barbour, R. (2009). Grupos focais (Duarte, M. F., Trad.). Porto Alegre: Artmed.

Bardin, L. (1977). Análise de conteúdo (Reto, L. \& Pinheiro, A.,Trad.). São Paulo: Edições 70/Livraria Martins Fontes.

Bastos, A., Fernandes, G. L., \& Passos, J. (2009). Analysis of school failure based on Portuguese micro data. Applied Economics Letters, 16, 1639-1643.

Bossa, N. A. (2002). Fracasso escolar: Um olhar psicopedagógico. Porto Alegre: Artmed.

Bzuneck, J. A. \& Sales, K. F. (2011). Atribuições interpessoais pelo professor e sua relação com emoções e motivação do aluno. Psico-USF, 16(3), 307-315.

Conselho Federal de Psicologia (2000). Resolução CFP n. 016/2000. Dispõe sobre a realização de pesquisa em psicologia com seres humanos. Recuperado: http://www.pol.org.br/pol/cms/pol/ legislacao/codigo_etica/.

Crahay, M. (2006). É possível tirar conclusões sobre os efeitos da repetência? (Rezende, N. L., Trad.). Cadernos de Pesquisa, 36(127), 223-246.

Ferraro, A. R. (1999). Diagnóstico da escolaridade no Brasil. Revista Brasileira de Educação, 12, 22-47.

Ferraro, A. R. (2004). Escolarização no Brasil na ótica da exclusão. Em A. Marchesi, \& C. H. Gil (Orgs.), Fracasso escolar: Uma perspectiva multicultural (Rosa, E., Trad.) (pp.48-65). Porto Alegre: Artmed.

Flick, U. (2009). Desenho da pesquisa qualitativa. (Costa, R. C., Trad.). Porto Alegre: Artmed.

Franco, A., \& Davis, C. (2011). Autoestima: Gênese e constituição de um atributo construído socialmente. Educação Temática Digital, 13(1), 99-118.

Guzzo, R. S. L., Mezzalira, A. S. C., Moreira, A. P. G., Tizzei, R. P., \&
Neto, W. M. F. S. (2010). Psicologia e educação no Brasil: Uma visão da história e possibilidades nessa relação. Psicologia: Teoria e Pesquisa, 26, 131-141.

Hanff, B. B. C., Barbosa, R., \& Koch, Z. M. (2002). Classes de Aceleração: "Pedagogia" da inclusão ou da exclusão? Ponto de Vista, 3(4),027-046

Ireland, V., Charlot, B., Gomes, C., Gusso, D., Carvalho, L. C. R., Fernandes, M., Ennafaa, R., \& Garcia, W. (2007). Repensando a escola. Brasília: UNESCO/MEC/INEP.

Jacomini, M. A. (2010). Por que a maioria dos pais e alunos defende a reprovação? Cadernos de Pesquisa, 40(141), 895-919.

Lagana-Riordan, C., Aguilar, J., Franklin, C., Streeter, C. Kim, J. Tripodi, S., \& Hopson, L. (2011). At-risk students's perceptions of traditional schools and a solutions-focused public alternative school. Preventing School Failure, 55(3), 105-114. doi: 10.1080/10459880903472843

Laville, C., \& Dionne, J. (1999). A construção do saber: Manual de metodologia da pesquisa em ciências humanas (Siman, L. M., Trad.). Porto Alegre: Artes Médicas.

Lei n. 9.394, de 20 de dezembro de 1996. (1996, 23 de dezembro). Estabelece as Diretrizes e Bases da Educação Nacional. Brasília: Diário Oficial da União, seção 1.

Lei 12.796, de 4 de abril de 2013. (2013, 4 de abril). Altera a Lei número 9.394 de 20 de dezembro de 1996. Brasília: Congresso Nacional.

Lucio, R., Hunt, E., \& Bornovalova, M. (2012). Identifying the necessary and sufficient number of risk factors for predicting academic failure. Developmental Psychology, 48(2), 422-428. doi: 10.1037/a0025939

Nunes, T. G., Pontes, F. A. R., Silva, L. I. C., \& Dell'Aglio, D. D. (2014) Fatores de risco e proteção na escola: Reprovação e expectativas de futuro de jovens paraenses. Psicologia Escolar e Educacional, 18(2), 203-210.

Oliveira, M., \& Freitas, H. (1997). Focus Group - método qualitativo de pesquisa: Resgatando a teoria, instrumentalizando o seu planejamento. Porto Alegre: Editora da UFRGS.

Osti, A., \& Brenelli, R.P. (2013). Análise comparativa das relações entre ensino e aprendizagem por professores e alunos. Psicologia Escolar e Educacional, 17(1), 55-63.

Parecer CNE/CEB $n^{\circ}$ 7/2010. (2010). Estabelece: Diretrizes Curriculares Nacionais Gerais para a Educação Básica. Brasil: Conselho Nacional de Educação.

Pasian, M. S., Veltrone, A. A., \& Caetano, N. C. S. P. (2012). Avaliações educacionais e seus resultados: Revelando ou 
omitindo a realidade brasileira sobre o fracasso escolar. Ensaios, 6(2), 440-456.

Patto, M. H. S. (1990). A produção do fracasso escolar: Histórias de submissão e rebeldia. São Paulo: Casa do Psicólogo.

Placco, V., André, M., \& Almeida, L. (1999). Estudo avaliativo das classes de aceleração na rede estadual paulista. Cadernos de Pesquisa, 108, 49-79.

Resolução CNE/CEB $n^{\circ}$ 4/2010. (2010, 13 de julho). Estabelece: Diretrizes Curriculares Nacionais Gerais para a Educação Básica. Brasil: Conselho Nacional de Educação.

Ribeiro, S. C. (1991). A pedagogia da repetência. Estudos Avançados, 12(5), 7-2.1

Rumberger, R. W. (2011). Introdution. Em R. W. Rumberger (Org.), Droping out (pp. 1-19). Recuperado: http://education.ucsb.edu/ rumberger/book/ch1.pdf
Robson, C. (1995). Real word research: A resource for scientist and practiotioner-researchs. Oxford: U.K.: Blackwell.

Sampieri, R. H., Callado, C. F., \& Lucio, M. P. B. (2013). Metodologia de pesquisa. Porto Alegre: Penso.

Secretaria Municipal de Educação de São Leopoldo [SMED-SL] (2012). Projeto Seguindo em Frente 2012. Arquivo da Secretaria Municipal de Educação, São Leopoldo, RS.

Torres, R. M. (2004). Repetência escolar: Falha do aluno ou falha do sistema? Em A. Marchesi, \& C. H. Gil (Orgs.), Fracasso escolar: Uma perspectiva multicultural (Rosa, E., Trad.). (pp.34-47). Porto Alegre: Artmed.

Vasconcellos, M. J. E. (2012). Pensamento sistêmico: O novo paradigma da ciência. São Paulo: Papirus.

Walkey, F. H., McClure, J., Meyer, L. H., \& Weir, K. F. (2013). Low expectations equal no expectations: Aspirations, motivation, and achievement in secondary school. Contemporary Educacional Psychology, 38, 306-315.

\section{Sobre as autoras}

Fernanda Aparecida Szareski Pezzi (nandaszareski@yahoo.com.br)

Psicóloga, mestre em Psicologia pela Universidade do Vale do Rio dos Sinos (Unisinos) e professora no Curso de Graduação em Psicologia da Sociedade Educacional Três de Maio (Setrem), RS.

Angela Helena Marin (angelahm@unisinos.br)

Psicóloga, mestre e doutora em Psicologia pelo Curso de Pós-Graduação em Psicologia da Universidade Federal do Rio Grande do Sul e professora dos Cursos de Graduação e de Pós-graduação em Psicologia da Unisinos, RS.

Artigo derivado da dissertação de mestrado de Fernanda Aparecida Szareski Pezzi, realizada sob a supervisão de Angela Helena Marin, apresentada no Programa de Pós-Graduação em Psicologia da Universidade do Vale do Rio dos Sinos, São Leopoldo - RS. Apoio financeiro: CNPq e CAPES. 
